\title{
Sexual Abuse Prevention Program for School Age Children
}

\author{
Mahbouba Sobhy Abd El Aziz ${ }^{1}$, Safaa Salah Ismail ${ }^{2}$, Howaida Moawad Ahmed ${ }^{3, *}$ \\ ${ }^{1}$ Department of Community Health Nursing, Faculty of Nursing, Benha University, Cairo, Egypt \\ ${ }^{2}$ Department of Pediatric Nursing, Faculty of Nursing, Helwan University, Cairo, Egypt \\ ${ }^{3}$ Department of Pediatric Nursing, Faculty of Nursing, Benha University, Benha, Egypt
}

\section{Email address:}

hwaida.ali@fnur.bu.edu.eg (H. M. Ahmed)

${ }^{*}$ Corresponding author

\section{To cite this article:}

Mahbouba Sobhy Abd El Aziz, Safaa Salah Ismail, Howaida Moawad Ahmed. Sexual Abuse Prevention Program for School Age Children. American Journal of Nursing Science. Vol. 6, No. 1, 2017, pp. 1-10. doi: 10.11648/j.ajns.20170601.11

Received: December 7, 2016; Accepted: December 26, 2016; Published: January 19, 2017

\begin{abstract}
Child sexual abuse is one of the most studied childhood traumatic events. The aim of this study was to evaluate the effect of sexual abuse prevention program for school age children. Research design: A quasi-experimental design was utilized to fulfill the aim of this study. Setting: The present study was conducted at one Primary School in Benha City. Sample: 100 students from previously mentioned setting by using a multi stage simple random sample technique were used in this study. Tools: Two tools were used in data collection, a structured interviewing questionnaire and pre/post child sexual abuse likert scale to assess children attitude. Result: Indicated that $74 \%$ of boys and $80 \%$ of girls aged $11 \leq 12$ years, $37.0 \%$ of boys and $35.0 \%$ of girls were exposed to sexual abuse at home, $73 \%$ and $46 \%$ of the studied school age children had unsatisfactory knowledge about sexual abuse prevention, in boys and girls respectively pre program, while $84 \%$ and $95 \%$ of them had satisfactory knowledge post program in boys and girls respectively. There were significant positive correlation of total children' knowledge and attitude with their age, gender, exposure to sexual abuse and parent relationship. Conclusion: The study concluded that the prevention program lead to significant improvement in children knowledge and attitude about sexual abuse prevention. Recommendation: Parents must be involved in the process of sexual abuse prevention and provision of instructional booklets for children to increase self protection knowledge and skills to avoid child sexual abuse.
\end{abstract}

Keywords: Child Sexual Abuse, Knowledge, Attitude, Prevention Program

\section{Introduction}

The children are the greatest investment of any society and the main basis for its development. School age children constitute a significant and important sector of the community who are constantly growing and developing. This basic dynamic character accounts for increased vitality and vulnerability to many health problems, so requires specific health promotion and prevention in relation to seeking health and using various resources to attain optimum health [17].

School age is one of the most important times in human development, experiences and relationships throughout childhood shape how children will ultimately relate with others and how they will perceive themselves. Often, these experiences go on to become internalized such that they affect a person's daily life experiences; one of the most devastating childhood events that have significant long-term and often lifelong consequences is Child Sexual Abuse (CSA). A variety of adult psychiatric disorders, including major depression, personality disorders, and self-harming behaviors have been linked to childhood sexual abuse [10].

Child abuse is any action by another person - adult or child that causes significant harm to a child; an abused child will often experience more than one type of abuse, as well as other difficulties in their lives. Child abuse can be domestic, physical, sexual, neglect, online, emotional, and bulling, but can just as often be about a lack of love, care and attention [21].

Child sexual abuse is often referred to as a silent epidemic either due to ignorance or denial of the problem; is any interaction between a child and an adult or an older youth in which the child is used for the sexual gratification of the adult. The CSA can include contact (touching of the vagina, penis, breast or buttocks, oral-genital contact or sexual 
intercourse) and non-contact behaviors (voyeurism, exhibitionism, or exposing the child to pornography, communication in a sexual way by phone, internet or face-toface) [4] \& [26].

Children by nature are particularly vulnerable to all types of abuse because of their temporary helplessness and dependence on adults and lack of knowledge about danger and self-protection. Learning about sexual abuse prevention is necessary, but it is not enough to ensure children's safety. Prevention and teaching about sexual abuse are the responsibility of parents and adults [9].

Worldwide it is estimated that, at least 1 in 10 girls and 1 in 20 boys experience some form of sexual abuse in childhood. Those who are sexually abused as children are more susceptible to depression, eating disorders, suicidal behavior and drug and alcohol problems later in life, and are more likely to become victims of sexual assault as adults. In many countries, children are taught how to recognize, react to and report abuse situations through school-based programs designed to help prevent sexual abuse [31].

Child sexual abuse is an issue that makes families extremely uncomfortable, because of it hurts to think about anyone harming children. However, unreported or untreated child sexual abuse not only scars children and destroys families, it also leaves offenders free to abuse and cripple future generations [26].

Children who are taught about preventing sexual abuse at school are more likely than others to tell an adult if they had, or were actually experiencing sexual abuse. The children who are sexually abused are more susceptible to depression, eating disorders, suicidal behavior and drug and alcohol problems later in life, and are more likely to become victims of sexual assault as adults [31].

Prevention programs were effective in increasing children's knowledge about sexual abuse; children who participated in prevention programs were also more likely than other children to protect themselves in a simulated abuse scenario in which they were asked to leave the school and go with someone they did not know. Also improve in protective behaviors and knowledge among children [31] \& [29].

The nurse focused on preventing the spread of diseases and treating ailments related to compulsory school attendance. The focus had shifted to preventive and promotive activities including case finding, integration of health concepts into school curricula, and maintained of healthful school environment. Nurse should raise awareness about prevention of sexual abuse among school age children; to teach children effectively, parents and teachers should be well informed about the complex impact of sexual abuse on children and other key facts. Whatever advice or instructions are given to children, they must be grounded in honest explanation and a good knowledge of the facts [5] \& [1].

\subsection{Significance of the Study}

In Egypt, the school age children from 6-12 years old are 7, 4464 million. School students in Egypt are influenced by the general problems of childhood, high density in class $(70$ student/ class), environmental population and educational stress as many are forced to operate in two shifts in a day. Age is a significant factor in sexual abuse. While there is risk for children of all ages, children are most vulnerable to abuse between the ages of 7 and 13. The median age for reported abuse is 9 years old. However, more than $20 \%$ of children are sexually abused before the age of 8 years [17] \& [18].

School aged children in Egypt need more education about prevention of sexual abuse. Children who have been on abuse prevention programs are more likely to tell an adult if they have been abused.

\subsection{Aim of the Study}

The study aimed to evaluate the effect of sexual abuse prevention program for school age children through:

- Assessing children knowledge and attitude regarding sexual abuse.

- Designing prevention program according to previously needs.

- Implementing and evaluating the outcome of the prevention program.

\subsection{Research Hypotheses}

- School age children who received program would have improved knowledge and attitude regarding prevention of sexual abuse.

\section{Subjects and Methods}

\subsection{Research Design}

A quasi-experimental design was utilized to fulfill the aim of this study.

\subsection{Setting}

The study was conducted at one Primary School in Benha City (El- Imam Mohammed Abdu School) which selected randomly from five Schools in Benha City.

\subsection{Sample}

100 students from the previously mentioned setting by using a multi stage simple random sample technique were used in this study, as follow; first stage: one primary school randomly selected from the five Governmental Primary Schools which found in Benh City (El-Thwra School, ElImam Mohammed Abdu School, El- Imam Mohamed Metwally El Shaarawy School, Ibn Khaldun School, Gameia El- Shabab El-Moslmeen School). Second stage: by using simple random sample two classes from grade six have been chosen, and third stage student of these classes stratified to boys and girls. From each stratum 50 girls and 50 boys were selected randomly.

\subsection{Tools of Data Collection}

Two tools were used for data collection.

First tool: A structured interviewing questionnaire was 
designed by the researchers in an Arabic language in the form of closed and open-ended questions after reviewing of related literature, which comprised of four main parts:

Part I: General characteristics of the studied children as (age, gender, residence, number of sibling, rank of family, house room, and parent relationship).

Part II: General characteristics of the studied children' parents as (age, education level and occupation).

Part III: History of children exposed to sexual abuse as (age of exposure, number of exposure, gender of person who do, degree of relation, telling someone about sexual abuse, and defense during sexual abuse).

Part IV: Children' knowledge about sexual abuse, it was composed of the following items as; meaning of sexual abuse, signs and symptoms of sexual abuse, route of sexual abuse, psychological problems associated with sexual abuse, common age of sexual abuse and prevention from sexual abuse).

Scoring system: the responses for each item are scored (3) for good, (2) for average and (1) for poor knowledge. The total scores of the knowledge of the question were 24 degree. Those who obtained $<60 \%$ were considered having unsatisfactory knowledge and those who obtained $\geq 60$ was considered having satisfactory knowledge.

Second Tool: Child Sex Abuse Attitude Scale was adopted from [7] that composed of 14 items, and children's responses were categorized into either agree, indifferent and disagree.

Scoring system: The total score of attitude scale was 42 degree and translated into positive and negative attitude, where scores $\geq 75 \%$ was graded as positive attitude, while scores $<75 \%$ was graded as negative attitude.

\subsection{Tools Validity and Reliability}

Tools were reviewed by a panel of five experts in the field of Pediatric Nursing and Community Health Nursing to test content validity and reviewed the tools for clarity, relevance, comprehensiveness, simplicity and minor modification was done. Testing reliability of the proposed tools was done statistically by Cronbach alpha test.

\subsection{Administrative Design}

Official letters were issued from Dean Faculty of Nursing, Benha University to the Director of the selected previously setting; explaining the aim of the study and asking permission for data collection and participation of children in research process.

\subsection{Ethical Considerations}

Each studied child and parents were informed about the purpose and benefits of the study at the beginning of the study. An oral consent was obtained from each studied child and parents before starting the data collection. Confidentiality and anonymity of each student were assured through coding of all data. The studied children were assured that data was used only for research purpose, participation is voluntary and the freedom to withdrawal from participation at any time.

\subsection{Pilot Study}

A pilot study was carried out on $10 \%$ of the studied children (10), to test the clarity and applicability of the study tools as well as estimation of the time needed to fill the questionnaire. Data obtained from the pilot study was analyzed and some items of questionnaire were modified and unnecessary were omitted. The necessary modifications on the study tools were done; those who participated in the pilot study were excluded from the main study sample.

Field work: The actual field work was carried out from the beginning of October, 2014 until the end of March, 2015 in the previously mentioned setting covering six months. An official approval to carry out the study was obtained from Dean of Faculty of Nursing to Director of Primary School. The researchers visited the previously mentioned setting two days/week (Monday and Thursday) from 11.00 A.m. to 1.00 P.m. until the predetermined sample size completed. The average time consumed to fill in the tools was 45 minutes.

\section{Program Construction}

To fulfill the aim of the current study, the following phases were adopted; assessment, planning, implementation, and evaluation phases. Assessment phase: This phase encompassed interviewing the studied children and parents to collect baseline data, at the beginning of the interview the researchers greeted the children, introduced themselves to each child included in the study, explained all information about the study purpose, duration, and activities and taken an oral consent. Data was collected by the researchers through administration of the tools to each child. The average time for the completion of each child interview was around 30-45 minutes, divided as 10-20 minutes for the first tool, and 1025 minutes for the second tool; average number collected was 5- 10 child / day. The total sample was divided into 10 subgroups that include 10 children for each session.

\subsection{Planning Phase}

Based on the needs identified in the assessment phase and relevant review of literature, the researchers developed a booklet about CSA prevention program. This was prepared in simple Arabic language to suit children' level of understanding and distributed to all recruited children in the study to achieve its objectives. As well as session's number and its contents, different methods of teaching and instructional media were determined accordingly.

\subsection{Implementation Phase}

The prevention program was implemented over six months, it was carried out in 5 sessions; 3 sessions for knowledge about the following: session one includes; meaning of children sexual abuse, signs and symptoms of sexual abuse 30 minutes. Session two includes; common age of exposure to sexual abuse, psychological problems 
associated with sexual abuse 30 minutes. Session three includes: routes of sexual abuse and prevention of sexual abuse children are taught self-assertion skills, a self-defense yell, and are encouraged to ask friends for help and to tell a trusted adult if an incident of abuse occurs.;(45 minutes). Two sessions for attitude were started first with discussion to assess children's feedback about attitude 5 minutes then sessions begins about protective attitude from sexual abuse 10 minutes. The duration of each session ranged between 30 45 minutes. At the beginning of each session, the researchers started by a summary about what was given through the previous session and objectives of the new one, taking into consideration using simple and clear language to suite the children. Different teaching methods were used including small group discussion, lectures and brainstorming roleplaying, behavior modeling, and rehearsal. The teaching aids used were brochures, colored posters, and laptop screen show videos about sexual abuse prevention and short stories. Each child of all studied groups obtained a copy of the educational program in Arabic language booklet included all topics. An open channel communication was achieved between researcher and children to ensure understanding, answer any question and to verify information given.

\subsection{Evaluation Phase}

The prevention program was evaluated through post test; by using the same of pretest tools that were conducted immediately after implementation of program, by comparing the change in children' knowledge and attitude.

\subsection{Limitation of the Study}

Difficulty in conducting the sessions during the teaching hours.

\subsection{Statistical Design}

Data analysis was done using Statistical Package for Social Science (SPSS) version 20.0 application. Qualitative data described by number and percent, where quantitative data described using means and standard deviation. Chi-square used to test relation between qualitative variables. Pearson correlation co-efficient (Pearson's $R$ ): tests for an association between two variables. A statistically significant difference was considered at $\mathrm{p} \leq 0.05$, and a highly statistically significant difference was considered at $\mathrm{p} \leq 0.001$.

\section{Results}

Table 1 . Shows that $74 \%$ of boys and $80 \%$ of girls aged 11 $\leq 12$ years with a mean age $11.2 \pm 2.3$ years. Where about $74 \%$ of boys and $76 \%$ of girls exist in urban area, $76 \%$ of boys had $3<6$ siblings mean while $88 \%$ of girls had $1<3$ siblings. According to the rank in the family $46 \%$ of boys were last meanwhile $30 \%$ of girls were first. Regarding parents' relationship $56 \%$ of boys had weak parents' relationship while $52 \%$ of girls reported moderate parents' relationship.
Table 1. Distribution of the studied children according to their general characteristics $(n=100)$.

\begin{tabular}{|c|c|c|c|c|}
\hline \multirow{2}{*}{ Items } & \multicolumn{2}{|c|}{ Boys } & \multicolumn{2}{|c|}{ Girls } \\
\hline & No & $\%$ & No & $\%$ \\
\hline \multicolumn{5}{|l|}{ Age in years } \\
\hline $10<11$ & 13 & 26.0 & 10 & 20.0 \\
\hline $11 \leq 12$ & 37 & 74.0 & 40 & 80.0 \\
\hline $\mathrm{X} \pm \mathrm{SD}$ & \multicolumn{4}{|c|}{$11.2 \pm 2.3$} \\
\hline \multicolumn{5}{|l|}{ Residence } \\
\hline Rural & 13 & 26.0 & 12 & 24 \\
\hline Urban & 37 & 74.0 & 38 & 76 \\
\hline \multicolumn{5}{|c|}{ Number of sibling } \\
\hline $1<3$ & 12 & 24 & 44 & 88 \\
\hline $3<6$ & 38 & 76 & 6 & 12 \\
\hline \multicolumn{5}{|l|}{ Rank in family } \\
\hline First & 5 & 10 & 15 & 30 \\
\hline Middle & 22 & 44 & 24 & 48 \\
\hline Last & 23 & 46 & 11 & 22 \\
\hline \multicolumn{5}{|l|}{ House room } \\
\hline $1-2$ & 31 & 62 & 44 & 88 \\
\hline $3-4$ & 14 & 28 & 3 & 6 \\
\hline $4-5$ & 5 & 10 & 3 & 6 \\
\hline \multicolumn{5}{|c|}{ Parents relationship: } \\
\hline Good/excellent & 10 & 20 & 12 & 24 \\
\hline Moderate & 12 & 24 & 26 & 52 \\
\hline Weak/fair & 28 & 56 & 12 & 24 \\
\hline
\end{tabular}

Table 2. Reveals that the studied children' parents age $<35$ with a mean age $32.5 \pm 2.5$ years. As regard educational level $48 \%$ of boys and $46 \%$ of girls stated that father had University education. Regarding occupation $100 \%$ of boy's fathers were working, meanwhile $74 \%$ of mothers were not working.

Table 2. Distribution of the studied children' parents according to their socio- demographic characteristics $(n=100)$.

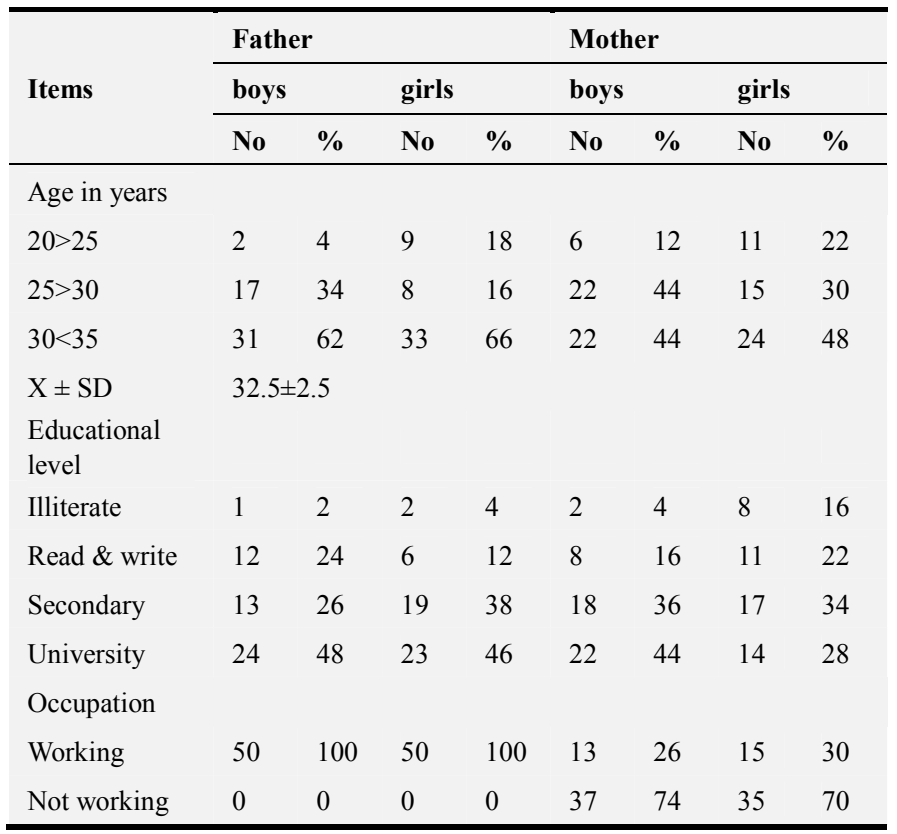

Figure 1. Illustrates that $70 \%$ of boys and $40 \%$ of girls were exposed to sexual abuse from other. 


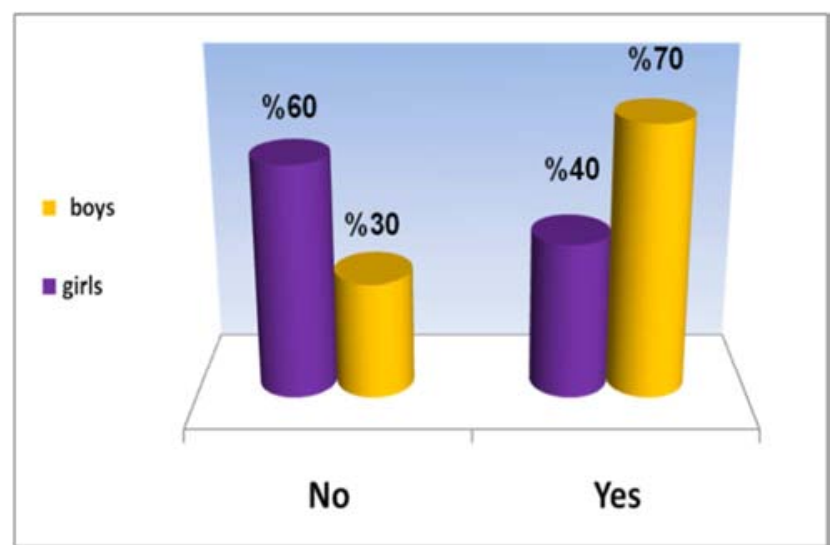

Figure 1. Percentage distribution of the studied children who exposed to sexual abuse (No. 100).

Table 3. Elaborates that the studied children's age of exposed to sexual abuse was $58 \%$ of boys were $11 \leq 12$ years, while $76 \%$ of girls were $10<11$ years. As regard number of children exposed to sexual abuse was $85.7 \%$ of boys and $75 \%$ of girls were exposed 1-3 times. $84 \%$ of boys and $80 \%$ of girls abuse from male. As regards degree of relation $56 \%$ of boys were relative while $58 \%$ of girls were stranger.

Table 3. Distribution of studied children history to sexual abuse exposed $(n=100)$.

\begin{tabular}{lllll}
\hline \multirow{2}{*}{ Items } & \multicolumn{3}{c}{ Boys $\mathbf{n}=\mathbf{5 0}$} & \multicolumn{2}{c}{ Girls $\mathbf{n}=\mathbf{5 0}$} \\
\cline { 2 - 5 } & No & $\mathbf{\%}$ & No & $\mathbf{\%}$ \\
\hline -Age of exposed & & & & \\
$10<11$ & 21 & 42 & 38 & 76 \\
$11 \leq 12$ & 29 & 58 & 12 & 24 \\
-Number of exposure & & & & \\
$1-3$ & 42 & 84 & 40 & 80 \\
$4-7$ & 8 & 16 & 10 & 20 \\
- Gender of person who do & & & & \\
Male & 43 & 86 & 47 & 94 \\
Female & 7 & 14 & 3 & 6 \\
-Degree of relation: & & & & \\
- Stranger & 22 & 44 & 29 & 58 \\
-Relative & 28 & 56 & 21 & 42 \\
-Telling someone about sexual abuse: & & & & \\
Yes & 30 & 60 & 18 & 36 \\
No & 20 & 40 & 32 & 64 \\
- Defense during sexual abuse: & & & & \\
Yes & 30 & 60 & 23 & 46 \\
No & 20 & 40 & 27 & 54 \\
\hline
\end{tabular}

Figure 2. Reveals that $37.0 \%$ of boys and $35.0 \%$ of girls were exposed to sexual abuse at home while $29.0 \%$ of boys and $25 \% .0$ of girls at social gathering and $14.0 \%$ of boys and $5.0 \%$ of girls at school.

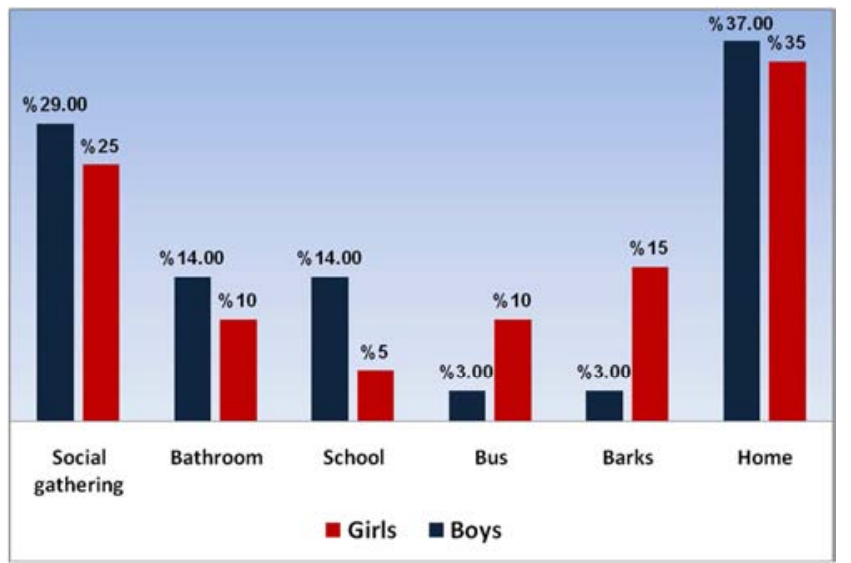

Figure 2. Percentage distribution of the studied children exposed to sexual abuse according to place $(n=100)$.

Figure 3. Illustrates that $50 \%$ of boys and $46 \%$ of girls were hated reaction after exposed to sexual abuse.

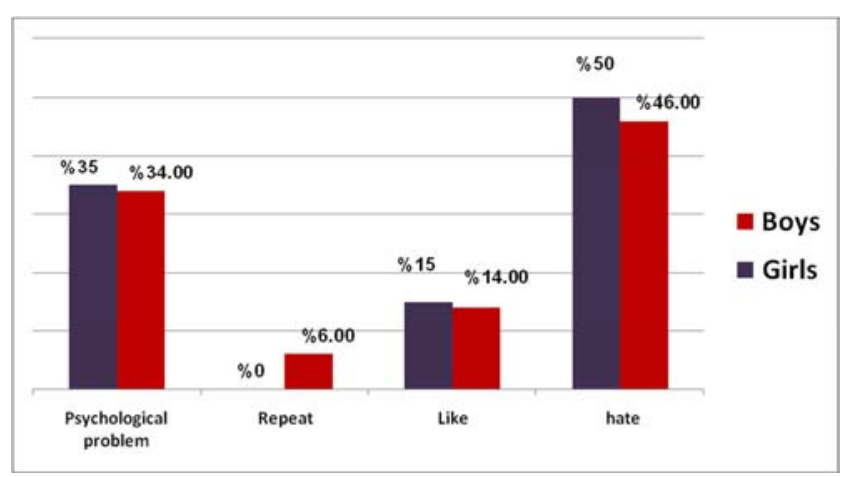

Figure 3. Percentage distribution of studied children according to their reaction after exposed to sexual abuse $(n=100)$.

Table 4. Shows that $84 \%$ of studied children had good knowledge for signs and symptoms about child sexual abuse. Moreover $79 \%$ of studied children had good knowledge for encouraging children to report sexual abuse. In addition there were highly statistically significant difference $(\mathrm{P}<0.001)$ between pre and post prevention program regarding total sexual abuse prevention.

Table 4. Percentage distribution of the studied children' knowledge regarding sexual abuse pre/post prevention program ( $n=100)$.

\begin{tabular}{|c|c|c|c|c|c|c|c|c|}
\hline \multirow{3}{*}{ Items } & \multicolumn{3}{|c|}{ Post program } & \multicolumn{3}{|c|}{ Pre program } & \multirow{3}{*}{$X^{2}$} & \multirow{3}{*}{$\mathbf{P}$} \\
\hline & Poor & Average & Good & Poor & Average & Good & & \\
\hline & $\%$ & $\%$ & $\%$ & $\%$ & $\%$ & $\%$ & & \\
\hline The meaning of child sexual abuse & 30 & 40 & 30 & 6 & 17 & 77 & 6.23 & $<0.05$ \\
\hline Sign and symptom of child sexual abuse & 52 & 35 & 13 & 4 & 12 & 84 & 3.15 & $<0.05$ \\
\hline The route of sexual abuse are & 71 & 23 & 6 & 5 & 26 & 69 & 5.71 & $<0.05$ \\
\hline Common age of sexual abuse & 53 & 31 & 16 & 6 & 24 & 70 & 5.08 & $<0.01$ \\
\hline $\begin{array}{l}\text { Psychological problems associated with sexual abuse } \\
\text { Prevention }\end{array}$ & 63 & 22 & 15 & 3 & 17 & 80 & 3.02 & $<0.01$ \\
\hline - Teaching children to avoid child sexual abuse & 42 & 46 & 12 & 3 & 27 & 70 & 4.06 & $<0.05$ \\
\hline -Giving children the skills to repel sexual abuse & 52 & 35 & 13 & 7 & 27 & 66 & 5.02 & $<0.05$ \\
\hline -Encouraging children to report sexual abuse & 66 & 28 & 6 & 5 & 16 & 79 & 3.91 & $<0.05$ \\
\hline
\end{tabular}


Figure 4 . Shows that $73 \%$ and $46 \%$ of studied children had unsatisfactory knowledge about sexual abuse prevention, in boys and girls respectively pre program, while $84 \%$ and $95 \%$ of them had satisfactory knowledge post program in boys and girls respectively. There was statistically significant difference $(\mathrm{P}<0.01)$ in children's knowledge with their gender.

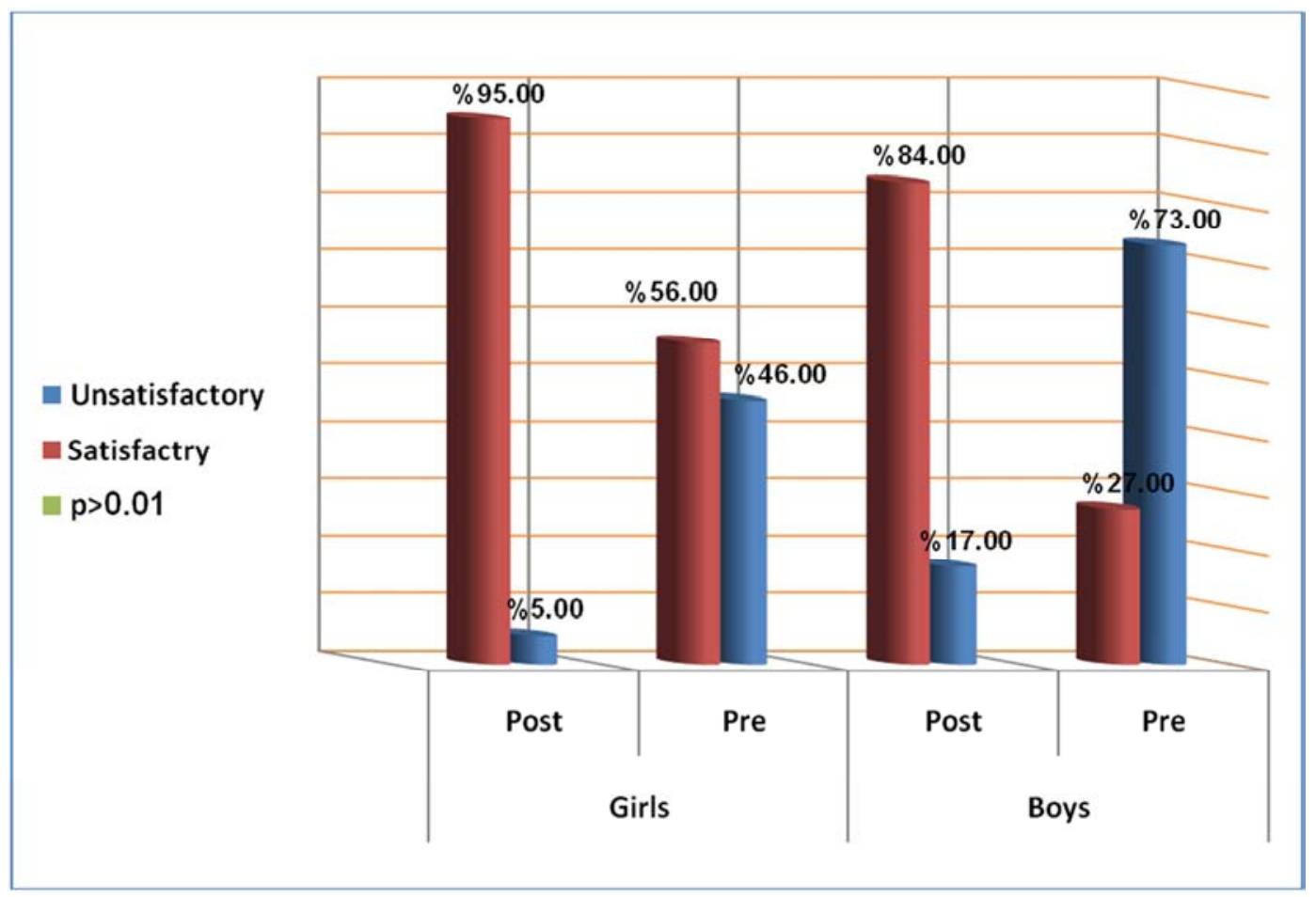

Figure 4. Relation between children gender and their knowledge about sexual abuse prevention pre/post program.

Table 5. Displays that there were statistically significant difference between children attitude pre and post program at all items.

Table 5. Percentage distribution of studied children' attitude towards sexual abuse $(n=100)$.

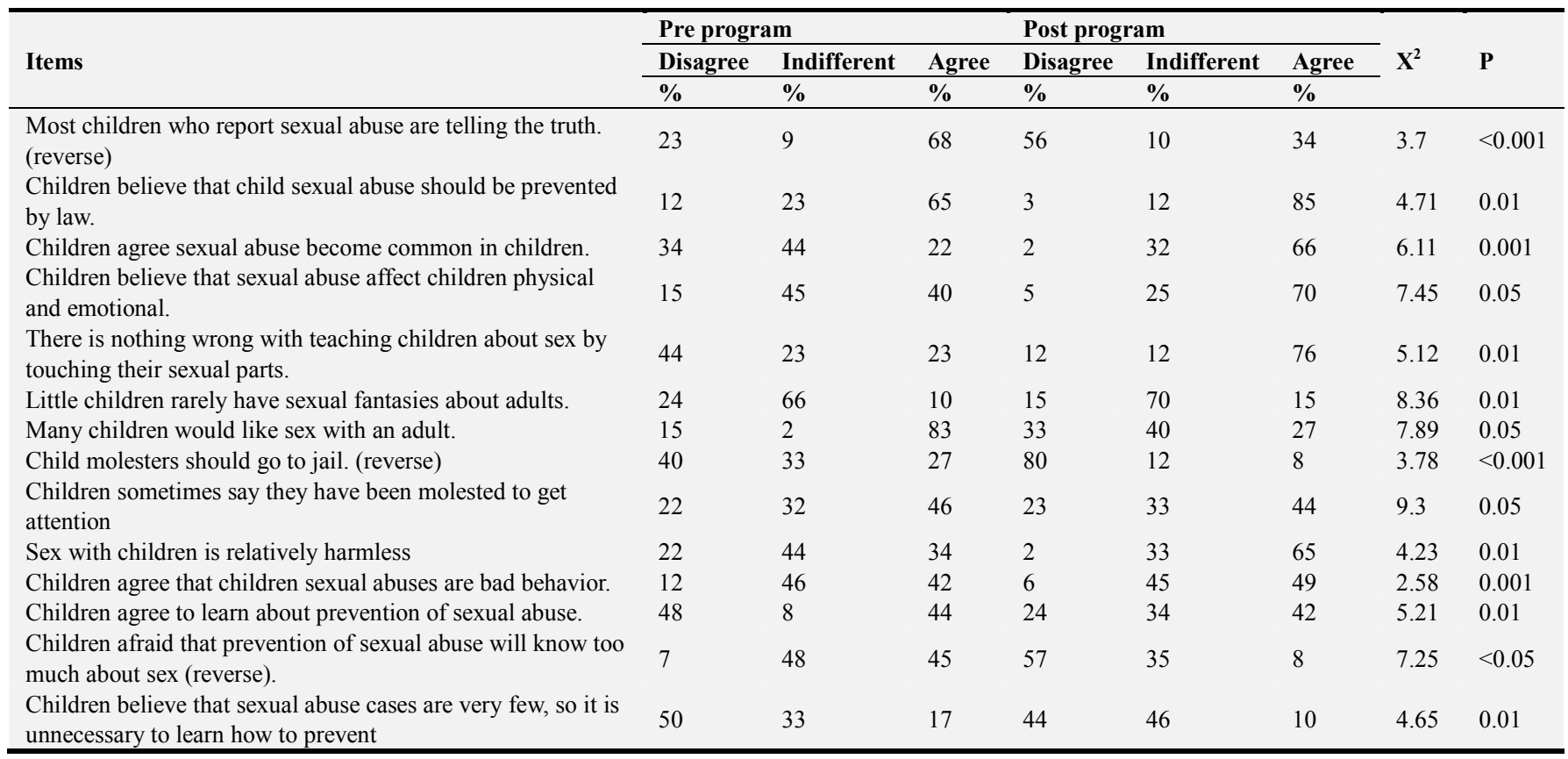

Figure 5. Reveals that there were significant statistically difference in children attitude and their gender pre/post program at $\mathrm{P}<0.001$. 


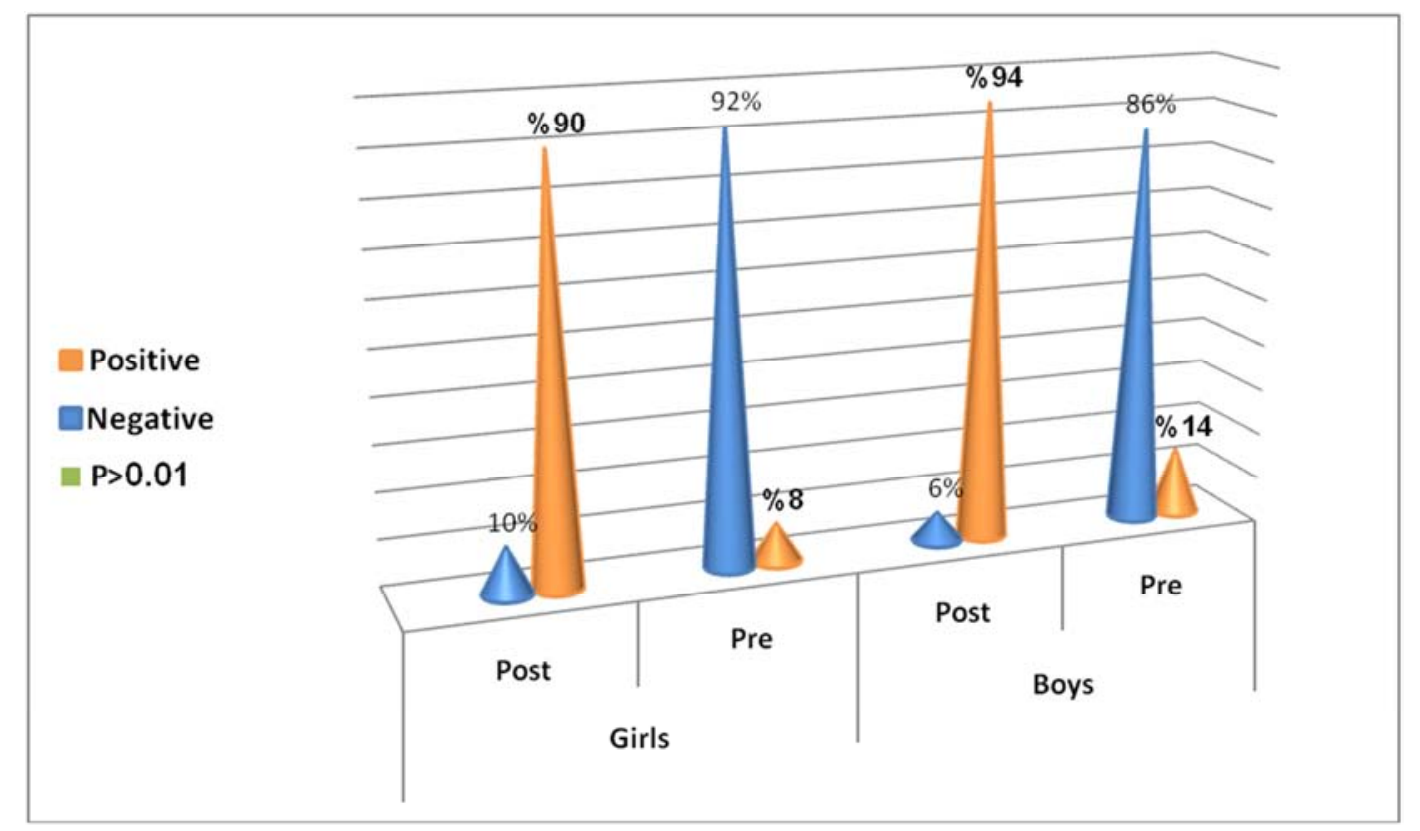

Figure 5. Relationship between the studied children gender and their attitude toward sexual abuse prevention pre/post program.

Table 6. Clarifies that significant positive correlation of total children' knowledge and total children' attitude with age, gender, exposed to sexual abuse and parent relationship, while regarding total children' knowledge there were significant positive correlation were found with rank and residence of children.

Table 6. Pearson correlation coefficient between total studied children' knowledge, attitude and their general characteristics.

\begin{tabular}{lllllllll}
\hline $\begin{array}{l}\text { Research } \\
\text { variables }\end{array}$ & age & Gender & Rank & Residence & $\begin{array}{l}\text { Number of } \\
\text { sibling }\end{array}$ & $\begin{array}{l}\text { House } \\
\text { room }\end{array}$ & $\begin{array}{l}\text { Exposed to } \\
\text { sexual abuse }\end{array}$ & Parent Relationship \\
\hline Total knowledge & & & & & & & & \\
$\mathrm{r}$ & 0.904 & 0.424 & 0.631 & 0.558 & 0.144 & 0.619 & 0.227 & 0.256 \\
$\mathrm{p}$ & $0.01^{*}$ & $0.08^{*}$ & $0.000^{*}$ & $0.01^{*}$ & 0.272 & 0.103 & $0.03^{*}$ & $0.05^{*}$ \\
Total attitude & & & & & & & \\
$\mathrm{r}$ & 0.231 & 0.327 & 0.125 & 0.044 & 0.209 & 0.081 & 0.731 & 0.258 \\
$\mathrm{p}$ & $0.07^{*}$ & $0.08^{*}$ & 0.340 & 0.738 & 0.159 & 0.619 & $0.000^{*}$ & $0.000^{*}$ \\
\hline
\end{tabular}

\section{Discussion}

Nurses have the opportunity to fulfill a variety of roles while caring for the abused child; nurses not only serve as caregiver, offering both physical and emotional support, but also as an advocator, using a wide range of knowledge, techniques and skills to provide care. Child sexual abuse prevention programs are of value because they provide information, support and empowerment [21-30].

The aim of this study was to evaluate the effect of sexual abuse prevention program for school age children. In relation to characteristics of studied children (table 1) the current study revealed that the recruited age of the studied children at age $10 \leq 12$ and with a mean age $11.2 \pm 2.3$ years. This finding was in an agreement with [2] who that studied physical and emotional abuse among Primary School Children in PortSaid City in Egypt and found that, the majority of child abuses occur among Primary School Children. Also in a study carried out by [15] was found that $93.1 \%$ of the respondents thought that it was necessary to provide children with sex education and more of between 7 and 12 years. This may be due to; this age is considered appropriate for children to understand the idea of sex education.

Regarding residence area of studied children about two third of boys and three quarter of girls exist in urban area, this was in an agreement with [11] who reported that, rapid demographic changes in the population, modernization, emigration, urbanization and changing social policies have all been linked with increase in child abuse. While about three quarter of boys had $3<6$ sibling mean while the majority of girls had $1<3$ sibling. According to the rank in family less than half of boys were last child meanwhile less than one third of girls were first child.

Regarding studied children' parents relationship it was obvious that, more than half of boys had weak relationship while about half of girls reported moderate parents' relationship. These finding in the same line with [14] who found significantly larger percentage of teenagers with history of sexual abuse suffered physical punishment at home compared to those who had no history of sexual abuse (305; $54 \%$ and $388 ; 37 \%, \mathrm{P}<0.001)$. This may be due to poor relationship between children and their parents.

As regard studied children's parents characteristics (table 
2), show that nearly two thirds of fathers age and nearly half of mothers age ranged between $30<35$ years old, regarding their educational level, nearly half of boys and girls stated that father had University education. And all of fathers were working, meanwhile about three quarter of mothers were not working. This is in a contrast with a study carried out by [16] who reported that, the majority of abused and neglect children's mothers were working. This may be due to the difference between study culture and place.

Concerning of studies children who exposed to sexual abuse (Figure 1), illustrated that less than three quarter of boys and more than one third of girls were exposed to sexual abuse from other. This finding was in an agreement with, [19] who studied predictors of violence in England and mentioned that, child abuse occurring more frequently in males than females. This finding is not in accordance with a study carried out by [28] reinforcing that between $20 \%$ and $40 \%$ of female children and just below $10 \%$ of male children, experienced child sexual abuse on a spectrum from exposure through unwanted touching to rape before the age of 18 years. Also [6] indicate $26.6 \%$ of girls and $5.1 \%$ of boys have experienced sexual abuse or assault by age 17. [13] Found that an overall child sexual abuse prevalence of $29.8 \%$, with the rate for females $(37.8 \%)$ being higher than that for males $(21.2 \%)$. Hugging and kissing in a way that disturbed the victims were the most reported type of child sexual abuse.

As regard studied children history to sexual abuse exposed (Table 3), illustrated that children age of exposed to sexual abuse were $11 \leq 12$ years, for about more than half of boys, while three quarter of girls were between age $10<11$ years. As regard number of children exposed to sexual abuse the majority of boys and three quarter of girls were exposed 1-3 times. The majority of boys and girls are abused from male. As regards degree of relation half of boys were relatives while more than half of girls were stranger. These findings were in line with studies of [27] said that child sexual abusers included $50 \%$ family members, $40 \%$ strangers, and $10 \%$ neighbors, where, 10 to $30 \%$ were strangers with the rest being family or known to the child, and $19 \%$ peers as abusers.

As regard studied children exposed to sexual abuse according to place (Figure 2), reveal that more than one third of boys and girls were exposed to sexual abuse at home while more than one quarter of them at social gathering and a few of them of at school. The result match with the study of [26] who studied 201 children participated in Brazil found $70 \%$ of cases abuse was intra-family, with the perpetrator being a family member or someone who lives with the child. Children who suffered extra-family abuse had been victimized by teachers and neighbors.

Regarding studied children reaction after exposed to sexual abuse (Figure 3), Illustrated that half of boys and girls were have hated reaction after exposed to sexual abuse. The result goes in line with study conducted by [24] who studied sexual violence and its health consequences for female children in Swaziland and mentioned that, victims of abuse were at risk for a variety of negative outcomes, they were more anxious and insecure, have lower self esteem, were lonely more likely to be rejected by their peers and were depressed. In addition to difficulties in relationship with other and school performance.

Concerning of, studied children' knowledge about sexual abuse (Table 4), showed that the majority of them had good knowledge about signs and symptoms of child sexual abuse. Also more than three quarter of them had good knowledge regarding encouraging children to report sexual abuse. In addition there were highly statistically significant difference pre and post prevention program related sexual abuse prevention. These result consistent with [15 \& 25] who said that participated in the child sexual abuse prevention training program had significantly higher levels of knowledge about sexual abuse and scores on their skills that may be helpful in avoiding sexual abuse (e.g., identifying, resisting, and reporting Inappropriate touch). These result consistent with a study carried out by [34], who found that there was a positive outcome of the child sexual abuse prevention program that Chinese children are able to learn the knowledge of disclosing the abuse. Also about $80 \%$ trained children were able to report someone about the abuse even if the abuser tells them to keep it a secret. Program participation, children in the intervention group demonstrated greater knowledge about sexual abuse prevention and higher levels of selfprotection skills compared with children in the wait-list control group. In study titled "School-based education programmes for the prevention of child sexual abuse", carried out by [35] revealed that programs are effective at building children's knowledge about sexual abuse and their preventive skills.

Concerning, relationship between studied children gender and their knowledge about sexual abuse prevention pre/post Program (Figure 4), show that the most of children had unsatisfactory knowledge about sexual abuse prevention, in boys and girls respectively, while the majority of them had satisfactory knowledge post program implementation. These result consistent with a study carried out by [23] that reported that child sexual abuse prevention programs for pre-scholar in Australia was effective and increasing children's knowledge about child sexual abuse and their ability to understanding of protective behaviors' in the event of an (attempted) abuse event or an inappropriate touch request. In addition in study of [10] found at El Salvador child sexual abuse information program prevention was very effective with there was no significant difference between gender of children.

Regarding studied children attitude towards sexual abuse (Table 5), pointed that there were statistical significant difference between children attitude pre/post program implementation. These result were inconsistent with [34] who found no significant shift was observed for the attitude of the girls and boys related sexual abuse prevention.

As regard relationship between studied children gender and their attitude regard sexual abuse prevention pre/post program (Figure 5), reveal that there were significant statistically difference in children attitude and their gender 
pre/post program implementation. These result were consistent with [29] which found in their study evaluated that there were significant improvements in protective behaviors with no significant difference between genders of children.

Concerning correlation between total studied children' knowledge, attitude and their characteristics (table 6), revealed that there was significant positive correlation of total children' knowledge and total children' attitude with age, gender, exposed to sexual abuse and parent relationship, while regarding total children' knowledge there were significant positive correlation were found with rank and residence of children. In addition [12]; [20]; [8]; [35] \& [6] stated that receiving training education is a good way to improve participants' knowledge and attitudes about child sexual abuse prevention.

\section{Conclusion}

The current study concluded that, the prevention program lead to significant improvement in studied children's knowledge and attitude about sexual abuse prevention

\section{Recommendation}

- Parents must be involved in the process of sexual abuse prevention program.

- Provision of instructional booklets for children to increase self protection knowledge and skills to avoid child sexual abuse.

- Increase positive feeling and decrease negative feeling about self.

- Replication of the study on a large sample and in different settings is recommended for generalization of results.

\section{References}

[1] Abd-Erazek, A., (2011): Assessment of student's awareness about influenza A/H1N1 in the secondary schools of girls at Benha City. Master Thesis, Faculty of Nursing, Benha University, P. 30.

[2] Abd-El Rhman, S., (2001): Assessment of physical and emotional abuse Among primary school children in Port- Said city, unpublished Master thesis, Suez Canal University, Faculty of Nursing pp. 80-85.

[3] Baker, C, K., Gleason, K., Naai 1, r., Mitchell, J., Trecker, C., (2012): Increasing Knowledge of Sexual Abuse: A Study with Elementary School Children in Hawai, Research on Social Work Practice, 23 (2) 167-178.

[4] Deblinger, E., Thakkar-Kolar, R, R,. and Berry, E, J., (2010): Caregivers' Efforts to Educate Their Children About Child Sexual Abuse, UMDNJ-School of Osteopathic Medicine.

[5] Finkelhor, D. (2007): Prevention of sexual abuse through educational programs directed toward children. Pediatrics, 120 (3): 640-645. Retrieved from: www.pediatrics.org/cgi/doi/10.1542/peds.
[6] Finkelhor, D., Shattuck, A., Turner, H. A., and Hamby, S. L. (2014): The lifetime prevalence of child sexual abuse and sexual assault assessed in late adolescence. Journal of Adolescent Health, 55, 329-333.

[7] Finnilä-Tuohimaa, K., Santtila, P., Sainio, M., Niemi, P. \&Sandnabba K. (2005): Connections between experience, beliefs, scientific knowledge, and self-evaluated expertise among investigators of child sexual abuse in Finland. Scandinavian Journal of Psychology 46, 1-10.

[8] Goldman, J. D. G., \& Bradley, G. L. (2011): Assessing primary school student-teachers' pedagogic implementations in child sexual abuse protection education. European Journal of Psychology of Education, 26, 479-493.

[9] Hitrec, G. (2015): Teaching children to protect themselves from sexual abuse Head of the Child Assault Prevention Programme (CAP) Croatia.

[10] Hurtado, A., . Katz, C., Ciro, D., Guttfreund, D. and Digna, N.,(2014): "Children's Knowledge of Sexual Abuse Prevention in El Salvador." Annals of Global Health 80 (2): March-April, PP. 103-107.

[11] Johnston, M., Phanhtharath, P., Jackson, $N$ and Brenda, S., (2010): "The bullying aspect of workplace violence in nursing ". JONA'S Health Care Low, Ethics and Regulation, 12 (2): $36-42$

[12] Kenny, M. C., Wurtele, S. K., \& Alonso, L. (2012): Evaluation of a personal safety program with Latino preschoolers. Journal of Child Sexual Abuse, 21, 368-385.

[13] Khaled, E., (2012): "Prevalence and pattern of child sexual abuse reported by cross sectional study among the University students, Sohag University, Egypt". Egyptian Journal of Forensic Sciences 2 (3): 89-96.

[14] Krishnakumar, P., Satheesan, K., and Geeta, M. G., Sureshkumar, K.,(2013): Prevalence and Spectrum of Sexual Abuse Among Adolescents, in Kerala, South India.

[15] Kurtuncu, M., Akhan, L, U., and Yildiz, H., (2015): The Sexual development and Education of Preschool Children: Knowledge and Opinions from Doctors and Nurses, Published online: 22 January, This article is published with open access at Springerlink.com

[16] Leeb, R., Paulozzi, L., Melanson, C., Simon, T, and Arias, L., (2008): "Child maltreatment surveillance: Uniform definitions for public health and recommendation data elements". Centers for Disease Control and Prevention, 320 (25): 76-173.

[17] Mahmoud, S., Yousif, $H$ and Ismail, S. (2011): Health promotion program to improve the life style of school children living in Slum Area in Helwan Governorate. Life Science Journal; 8 (4): 618.

[18] Mandy (2015): Teaching Sex Abuse Prevention In Schools Is Critical, Available at: https://healingbeyondsurvival.wordpress.com/2015/05/01/teac hing-sex-abuse-prevention-in-schools-is-critical/

[19] Martin, E. and William, M., (2008):"Is your hospital safe, Disruptive behavior and workplace bullying". Hospital topics, Journal of the Royal Society of Medicine, 86 (3): 8-21.

[20] McKee, B. E., \& Dillenburger, K. (2012): Effectiveness of child protection training for pre-service early childhood educators. International Journal of Educational Research, 53, 348 . 
[21] National Society for the Prevention of Cruelty to Children (2016): Child abuse and neglect available at: https://www.nspcc.org.uk/preventing- abuse/child-abuse-andneglect $10-6$

[22] Pizzato, E, S., and Bernardes, M, W., (2006): Development of a questionnaire for the assessment of sexual abuse in children and estimation of its discriminant validity: a case-control study, Journal. Pediatra. (RioJ.) vol. 82 no. 6 Porto Alegre.

[23] Pitts, C., (2015): Child sexual abuse prevention programs for pre-schoolers: A synthesis of current evidence, Royal Commission into Institutional Responses to Child Sexual Abuse, Sydney.

[24] Reza, A., Breiding, M., Gulaid J., Mercy, J., Blanton, C. and Mthethwa, Z., (2009): Sexual violence and its health consequences for female children in Swaziland: A cluster survey study Lancet, 373: 1966-1972.

[25] Rheingold, A, A., Zajac, K., Patton, M., de Arellano, M. Saunders, B., Kilpatrick, D., and Chapman, J. E., (2014): Child Sexual Abuse Prevention Training for Childcare Professionals: An Independent Multi-Site Randomized Controlled Trial of Stewards of Children, Published online: 12 July, Society for Prevention Research.

[26] The Child Assessment Center (2014): Child Sexual Abuse Facts, Available@: http://www. cachouston.org/child-sexualabuse-facts.

[27] Topping, K, J., and Barron, I, G., (2010): School-based Abuse Prevention: Effect on Disclosures, Published online: 4 July, Springer Science, Business Media, LLC
[28] Walsh, K., and Brandon, L., (2011): Their Children's First Educators: Parents' Views About Child Sexual Abuse Prevention Education, Published online: 14 September, Springer Science+Business Media, LLC.

[29] Walsh, K., Zwi, K., Woolfenden, S., and Shlonsky A. (2015): School-based programmes for the prevention of child sexual abuse, available at: http://onlineThe Cochrane Library. wiley.com.

[30] White, L., Duncan, G. and Baumle, W. (2010): Bruising in children who are assessed for suspected physical abuse. Ann Emerg Med J., 39 (5): 9-50, 3.

[31] Wiley (2015): Teaching children in schools about sexual abuse may help them report abuse, Science Daily available at http://www.sciencedaily.com/releases/.

[32] Wurtele, S, K., Moreno, T., and Kenny, M, C., (2008): Evaluation of a Sexual Abuse Prevention Workshop for Parents of Young Children.

[33] Zhang, W., Chen., J., Feng, Y., Li, J., Liu, C., and Zhao, X., (2013): Evaluation of a Sexual Abuse Prevention Education for Chinese Preschoolers, Research on Social Work Practice, Vol. 24 (4) 428-436.

[34] Zhang, W., Chen, J., and Liu, F., (2015): Preventing Child Sexual Abuse Early Preschool Teachers' Knowledge, Attitudes, and Their Training Education in China, 1-8, sgo.sagepub.com.

[35] Zwi, K., Woolfenden, S., Wheeler, D. M., O'Brien, T., Tait, P., \& Williams, K. J. (2009): School-based education programmes for the prevention of child sexual abuse, Issue 3. 